\title{
A BIBLIOGRAPHIC ANALYSIS OF WATER EFFICIENCY AMONG GREEN BUILDING RATING TOOLS: LEED AND ESGB
}

\author{
ZHou, W. W. ${ }^{1,2}-$ WU, D. J. ${ }^{1 *}-$ CHeng, X. X. ${ }^{1 *}-$ LuO, C. W. ${ }^{1}-$ TAN, F. X. ${ }^{1}-$ ZHANG, Z. L. ${ }^{2}$ \\ ${ }^{I}$ School of Municipal and Environmental Engineering, Shandong Jianzhu University, Jinan, \\ 250101 Shandong, China \\ (phone/fax: +86-531-8636-7291) \\ ${ }^{2}$ Shandong Urban Construction Vocational College, Jinan, 250103 Shandong, China \\ (phone/fax: +86-531-8970-9958) \\ *Corresponding authors \\ e-mail:wdj@sdjzu.edu.cn, chengxiaoxiang18@sdjzu.edu.cn; phone/fax:+86-531-8636-7291
}

(Received 22 $2^{\text {nd }}$ Apr 2019; accepted 12 $2^{\text {th }}$ Jul 2019)

\begin{abstract}
The green building rating tools can be used to evaluate, and promote the building industry's sustainability, but previous relevant research on the comparative analysis were mainly conducted at the general, category or criteria level, very little research has been done from the indicator level via statistical analysis. Especially, research on the comparison of water efficiency is rare. To this end, this paper will focus on a thorough and comprehensive comparison of the water efficiency between Leadership in Environmental and Energy Design (LEED, US) and Evaluation Standard of Green Building (ESGB, China). The comparison of the specific terms includes six aspects, i.e. macroscopic, building water use, landscape water use, heat and cooling system use water, nontraditional water source utilization and water monitoring system. The similarities and differences of water efficiency standards are described. In the end, the development direction of domestic water efficiency technology is pointed out and meanwhile, a more reasonable water efficiency standard in China is suggested. The LEED is also suggested to use the detailed items of the non-traditional water source utilization from ESGB for reference. The research results would serve as a useful reference for both industry practitioners and academics that are interested in green buildings.
\end{abstract}

Keywords: building certification systems, water, sustainability, green rating systems, comparative analysis, research review

\section{Introduction}

The building industry gives great contribution in creating monetary values and jobs, and makes profound influence on the economy and society (Kang et al., 2016; Lin and Liu, 2015; Liu and Lin, 2016; Marjaba and Chidiac, 2016). However, the development of building industry causes more consumption on the natural resources and energy, simultaneously creates more social problems with carbon emissions, environmental degradation and global warming, etc. According to the World Business Council for Sustainable Development, building block production accounts for approximately $40 \%$ of total energy consumption (WBCSD, 2008), 30\% of greenhouse gas (GHG) emission (UNEP SBCI, 2008), 17\% of fresh water consumption, $25 \%$ of the harvested wood (Smith, 2005; Say and Wood, 2012), and produces 45\%-65\% of disposal waste in landfills (Yudelson, 2008). Hence, the industry is controversial. As a consequence, how to reduce the adverse environment impacts of the building industry becomes a hot point issue.

A Green Building Rating System (GBRS), defined by Nguyen and Atlan (2011), is a tool that can be used to evaluate and promote the sustainability of building industry. 
With the guidance and better insights into sustainability through information analysis, valuation and comparisons, the GBRS can provide the following suggestions on the green buildings:

i. Minimize environment impact of the buildings

ii. Measure buildings' effect on the environment

iii. Objectively evaluate and judge buildings' development (Awadh, 2017)

Many GBRSs have been put into practice in the worldwide (Haapio and Viitaniemi, 2008; Kyvelou and Sinou, 2013; He et al., 2018; Ding et al., 2018), such as Building Research Establishment Environmental Assessment Method (BREEAM, United Kingdom) (BREEAM, 2016), Leadership in Environmental and Energy Design (LEED, the United States) (LEED, 2013), Evaluation Standard for Green Building (ESGB, China) (ESGB, 2014), Green Mark (GM, Singapore) (Green Mark, 2013), Comprehensive Assessment System for Building Environmental Efficiency (CASBEE, Japan) (CASBEE,2014), Green Star (GS, Australia) (Green Star,2015) and ITACA (Italy) (ITACA, 2015). Due to the fact that the GBRSs can promote sustainable practices and play an important role to the development of sustainable buildings, an increasing number of researchers have focused on the comparison the methods and tools used to evaluate the environmental performance of different kinds of buildings (US Green Building Council, 2018).

In the past years, more researchers focused on the development of the assessment standards and the refinement of the existing ones to reduce the environmental impact of the green buildings (Cole, 2006; Ding, 2008; Wang et al., 2012). For example, Mattoni et al. (2018) analyzed the five well known GBRSs (i.e. CASBEE, GS, BREEAM, LEED and ITACA) in detail to find their differences and similarities on six macro-areas (site, water, energy, comfort and safety, materials and outdoor quality), and further explored which issues exhibited more influence on the final performance rate of each systems. Lee (2013) compared the five representative assessment schemes (i.e. BREEAM, LEED, CASBEE, BEAM Plus (Hong Kong) and ESGB) and found that the BREEAM and LEED are the most comprehensive, two-phase certification method is preferable of LEED, CASBEE and BEAM plus, and the weighting coefficients adopted by ESGB were the most representative. Feng and Hewage (2014) took the energy saving performance of green vegetation on LEED certified buildings into consideration and found the green vegetation is not cost-effective in winter months or cold climatic regions due to low energy saving performance, and hence, recommend to improve overall energy performance in green buildings. Li et al. (2017) conducted a systematic review of the existing literature on green building assessment methods through comparative analysis and found the main contributing authors and represented countries, the number of comparative assessment methods, and the current topic is focused on the general comparison and the category comparison. The future research should be developed to the indicator comparison. However, there is no literature that does comprehensive comparisons on water efficiency among GBRSs in detail. Therefore, the objective of this paper is to carry out a comparative analysis on the indicator of water efficiency between LEED and ESGB from six aspects, i.e. macroscopic, building water use, landscape water use, heat and cooling system use water, nontraditional water source utilization and water monitoring system.

This paper begins with the background review of LEED and ESGB, followed by the research methodology for statistical analysis among the paper samples to present the 
evidence of the basis on the topic selected. Then, the six detailed aspects are compared within the water efficiency indicator. Finally the current research focuses are presented; with future development direction is suggested. The results of the systematic review in this paper will serve as a useful reference for both industry practitioners and academics that are interested in the water efficiency of green buildings.

\section{Overview of LEED and ESGB}

\section{LEED}

LEED was developed by the US Green Building Council (USGBC) for the US Development of Energy (Wu et al., 2016; Hu et al., 2017; Schwartz and Raslan, 2013), and has become the most widely used GBRS in the world. Available for virtually all buildings, communities and home project types, LEED assessments have been carried out in 41 countries, including Canada, Brazil, Mexico, India and China (Lee, 2013; Gelowitz and McArthurand, 2018; Kern et al., 2016; Chen and Lee, 2013). LEED provides a frame work to create healthy, highly efficient and cost-saving green buildings. LEED certification is a globally recognized symbol of sustainability achievement. Now more than 2.2 million square feet is LEED certified every day with more than 92,000 projects using LEED. LEED buildings can save energy, water, resources, generate less waste and support human health. The LEED 1.0 of new construction was first launched at USGBC in 1998 (Altomonte and Schiavon, 2013; Wu et al., 2017), and LEED 2.0 based on modifications made during the pilot period was released. Then the LEED continued to be modified to respond to the needs of the market, and has been expanded to cover different kinds of buildings types. The detailed development of LEED can be seen in Figure 1 (Doan et al., 2017).

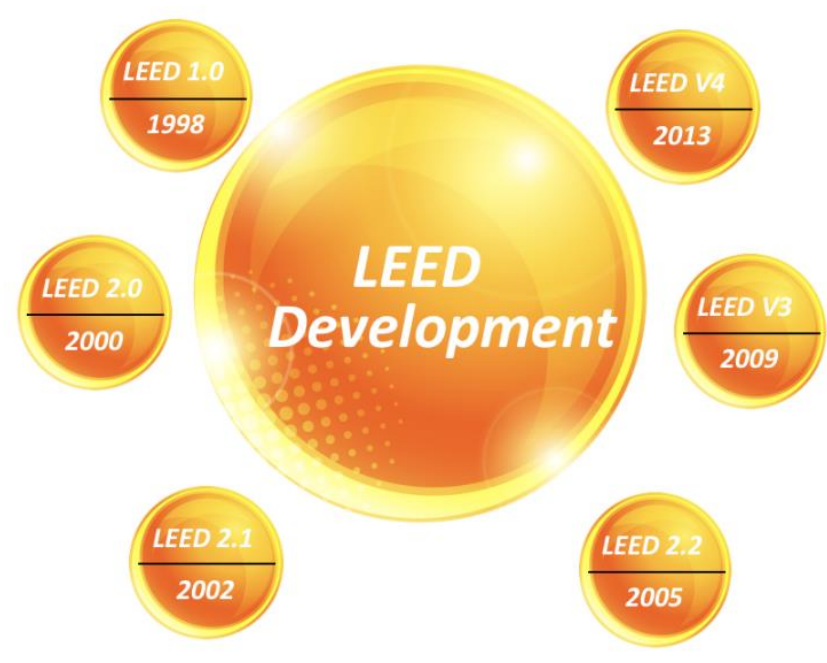

Figure 1. LEED development history

Currently, LEED v4 is the newest version. It focuses on materials to get a better understanding of what is in them, and the effect of those components on human health and the environment. A stronger and performance-based approach is used to indoor environmental quality for better occupant comfort. In addition, it brings the benefits of 
smart grid thinking to the forefront with a credit that rewards projects for participating in demand response programs and provides a clear picture of water efficiency by evaluating total building water use.

As Table 1 illustrated, there are seven categories that cover (maximum number of points for each category in parentheses): location and transportation (32), sustainable sites (10), energy and atmosphere (33), water efficiency (11), materials and resources (13), indoor environmental quality (16), regional priority (4) and innovation (6); the maximum possible total score is 125 points. For example, location and transportation category includes eight indicators (maximum number of points for each indicator): neighborhood development location (16), sensible land protection (1), high-priority site (2), surrounding density and diverse uses (5), access to quality transit (5), bicycle facilities (1), reduced parking footprint (1), green vehicles (1). Each category has the prerequisites condition, which means that the criteria must be included before a project can be evaluated and the core credits given for meeting or exceeding the requirements in the categories (Alyami and Rezgui, 2012). As shown in Table 2, the LEED buildings awarded points for individual aspects of assessment are summed and compared against a rating scale to yield an overall grade, which may be certified (40-49 points), silver (50-59 points), gold (60-79 points) or platinum (> 80 points).

Table 1. The comparison of LEED and ESGB on categories

\begin{tabular}{c|c|c}
\hline $\begin{array}{c}\text { GBRS } \\
\text { (maximum number of the } \\
\text { points for each category) }\end{array}$ & LEED V4 (125) & ESGB 2014 (110) \\
\hline & Location and transportation (32) & Sustainable site and outdoor environment (21) \\
& Sustainable sites (10) & Energy use (24) \\
Energy and atmosphere (33) & Water saving (20) \\
Category & Water efficiency (11) & Material use (17) \\
(maximum points) & Materials and resources (13) & Indoor environmental quality (18) \\
& Indoor environmental quality (16) & Innovation (10) \\
& Regional priority (4) & ----- \\
\hline
\end{tabular}

Table 2. The comparison of LEED and ESGB on certified grade

\begin{tabular}{c|c|c}
\hline GBRS & Grade & Credits \\
\hline & Certified & $40 \sim 49$ \\
LEED & Silver & $50 \sim 59$ \\
& Gold & $60 \sim 79$ \\
& Platinum & $>80$ \\
\hline \multirow{2}{*}{ ESGB } & 1 -star & $50 \sim 60$ \\
& 2 -star & $60 \sim 80$ \\
& 3 -star & $>80$ \\
\hline
\end{tabular}

\section{ESGB}

In China, with the rapid increasing for building industry, the green building began to be explored in the early 1980s in response to the increasing energy use of the residential sector, especially for air-conditioning and heating (Lee, 2013). In March 2006, the first 
Evaluation Standard of Green Building (GB/T 50378-2006) was promulgated by the Ministry of Construction (Lee, 2012). Then it was updated in 2014 with the second version ESGB (GB/T 50378-2014) (ESGB, 2014). From the beginning of 2008 to the end of 2015, the green building certification review system was implemented in China. There were 4071 certified projects with the total area of 472 million square meters for green building, among which 3859 projects with the area of 444 million square meters were green design, and 212 projects with the area of 28 million square meters were green operation (Ding et al., 2018).

There are six categories that cover (maximum number of points for each category in parentheses): Sustainable site and outdoor environment (21), Energy use (24), Water saving (20), Material use (17), Indoor environmental quality (18) and Innovation (10); the maximum possible total score is 110 points. For example, sustainable site and outdoor environment category includes four indicators (maximum number of points for each indicator): land saving (7.14), outdoor environment (3.78), transportation and public service (5.04), site design and ecology (5.04). The score were evaluated by both prerequisites condition and the core credits system. As is shown in Table 2, the overall grade of ESGB buildings is on a scale of 1-star (50 - 60 points), 2-star (60-80 points) and 3-star (above 80 points).

\section{Research methodology}

\section{Three stages research methodology}

Due to the fact that so many researchers have made fully comparisons between different GBRSs from different directions, the three stages was practiced in this review to find a new direction to conduct the analysis.

In stage 1, a thorough search was implemented in the three major data bases: Science Direct, Engineering Village, and Scopus with the key words: LEED, ESGB, green building, assessment methods, sustainable building, energy efficiency, water efficiency, environment protection, indoor environment quality, sustainable site. These reviews mainly cover papers published from 2001 to 2017. After careful reviews of paper contents and removal of duplicates, a total of 73 articles were identified for the next analysis.

During stage 2, the statistical analysis of these 73 articles was carried out to find and identify the research direction from the following aspects:

(i) The statistical number of papers in each year, as illustrated in Figure 2. From 2013, more and more researchers focused on the GBRSs innovation and comparison, because the GBRSs are the principle and tool to promote the development of green buildings. Based on these researches so many countries began to implement their own GBRS according to the local condition.

(ii) The statistical number of papers in each country based on the first author's nationality, as explained by Figure 3. Currently, green building development in China is still at its initial stage (Zhu et al., 2017; Borong et al., 2016). The BREEAM and LEED are still occupying the dominant position in the green building evaluation market with their mature experience of the green building development in UK and the US. So the papers from Chinese researchers get the main percentage for nearly about $19 \%$. As a developing country, Chinese researchers still has a long way to explore the green building development in theory and practice. 


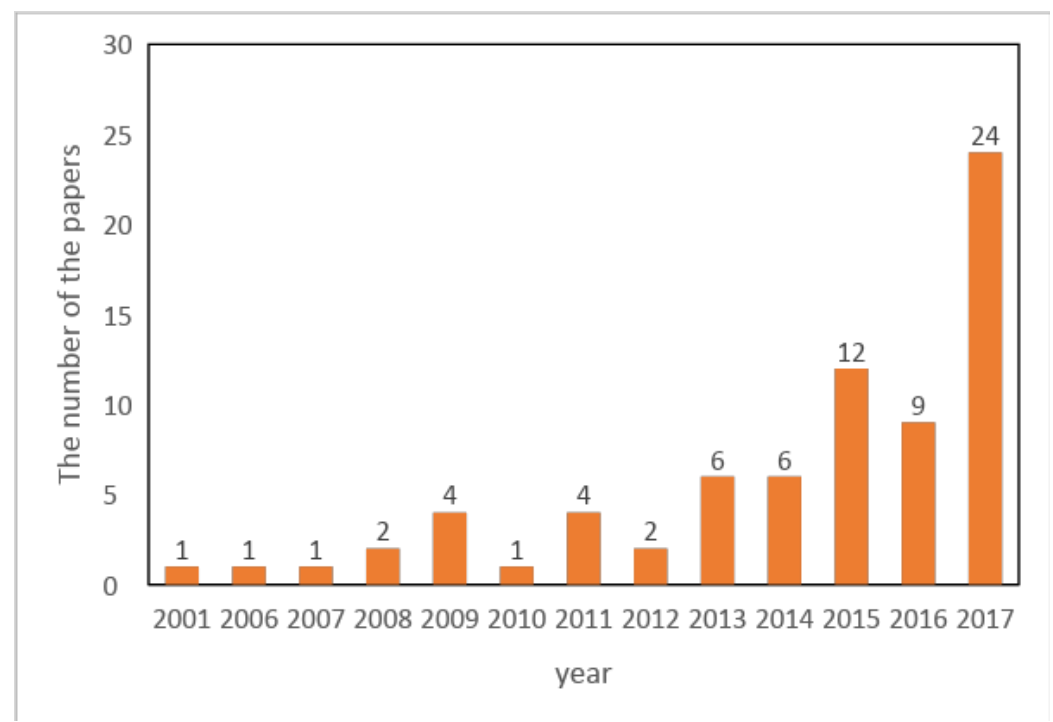

Figure 2. The number of papers in each year of the selected articles

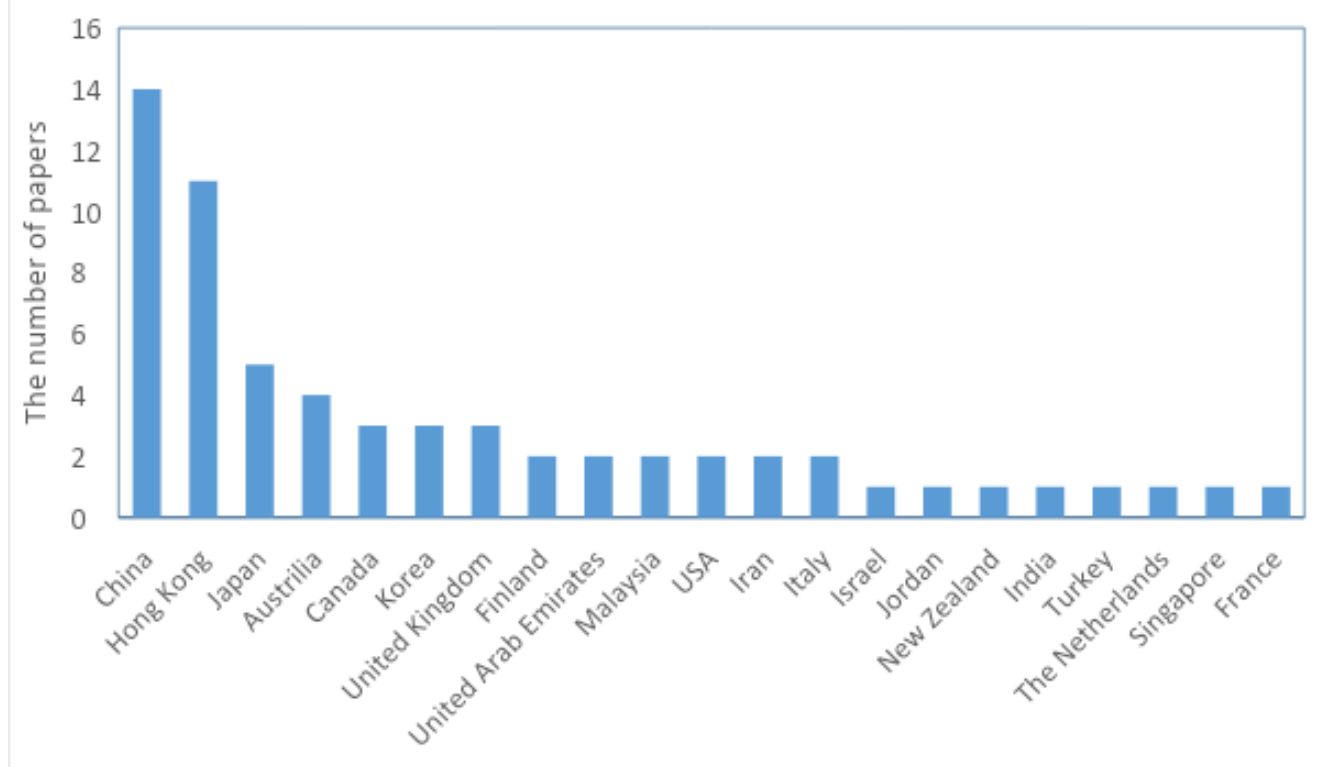

Figure 3. The number and the percentage of the papers in each country of the selected papers

(iii) The result to determine the main contributing authors. The formula proposed by Howard for determining the contribution of authors to a multi-authored article was adopted (Howard et al., 1987). The formula is shown in Equation 1:

$$
\text { Score }=\frac{1.5^{\mathrm{n}-1}}{\sum_{i=1}^{n} 1.5^{\mathrm{n}-\mathrm{i}}}
$$

where $n$ denotes the number of authors of the paper and $i$ is the order of each author. As indicated in Table 3, Lee from the Hong Kong Polytechnic University is the most active 
author by far. The research from Lee focused on the comprehensive comparison of the GBRSs and the indicator of energy use from different assessment methods. Sharifi focused on the topic of the neighborhood sustainability assessment with different GBRSs (Sharifi, 2016; Sharifi and Yamagata, 2016; Sharifi and Murayama, 2013, 2014).

Table 3. Main contributing authors

\begin{tabular}{c|c|c|c}
\hline Author & Number of papers & Score point & Affiliation \\
\hline Lee W. L. & 6 & 3.92 & Hong Kong Polytechnic University \\
Sharifi Ayyoob & 4 & 2.80 & Nagoya University \\
Ann T. W. Yu & 4 & 1.84 & Hong Kong Polytechnic University \\
Haapio Appu & 2 & 1.60 & Helsinki University of Technology \\
Jian Zuo & 2 & 1.39 & University of Adelaide \\
Illankoon I. M. C. S. & 2 & 0.89 & Western Sydney University \\
\hline
\end{tabular}

(iv) Four levels comparison of the GBRSs of the selected articles. A comprehensive analysis of the selected papers is mainly compared at four levels as is shown in Table 4: (a) general comparison (80\%); (b) category comparison (71\%); (c) criterion comparison (51\%); (d) indicator comparison (31\%). This result is similar with the investigation result from $\mathrm{Li}$ et al. (2017). Thus it can be seen that the indicator comparison is still at a low level for their complicated characteristic in a very detailed sector. Among these indicators, the water efficiency comparison gets the lowest percentage (1\%). At the same time, more researchers focused on the comparison on the energy use $(11 \%)$ and environment (11\%) etc. This phenomenon can be explained by the following reasons: (a) The experts in the water utilization sector focused on the development of the water treatment process, chemistry and material, and little relevant experts focused on the green buildings' demand. (b) Water efficiency get relatively lower points from the total scheme, which is easy to be ignored by the auditors and the owners. (c) It is difficult for the building to get more points from water efficiency indicator even after doing some improvements, but it is much easier to be optimised from the energy sector etc. So in this paper, the water efficiency indicator in LEED and ESGB is chosen to make a comparison in order to give a useful reference for both industry practitioners and academics that are interested in the GBRSs.

Table 4. Four levels of the comparison

\begin{tabular}{|c|c|c|}
\hline Comparison topics & Sub-topics & Percentage of papers \\
\hline Level 1: general comparison & $\begin{array}{ll}\text { - } & \text { History } \\
\text { - } & \text { Certification levels } \\
\text { - } & \text { Schemes available }\end{array}$ & $80 \%$ \\
\hline Level 2: category comparison & - Weighting or points & $71 \%$ \\
\hline Level 3: criterion comparison & $\begin{array}{ll}\text { - } & \text { Mandatory criteria } \\
\text { - } & \text { Prerequisite } \\
\text { - } & \text { Minimum points }\end{array}$ & $51 \%$ \\
\hline Level 4: indicator comparison & $\begin{array}{ll}\text { - } & \text { Energy }(11 \%) \\
\text { - } & \text { Environment }(11 \%) \\
\text { - } & \text { Materials and waste }(4 \%) \\
\text { - } & \text { Project management }(4 \%) \\
\text { - } & \text { Water efficiency }(1 \%)\end{array}$ & $31 \%$ \\
\hline
\end{tabular}


In terms of stage 3, the comparison of the water efficiency is analyzed from six aspects, i.e. macroscopic, building water use, landscape water use, heat and cooling system use water, nontraditional water source utilization and water monitoring system. Detailed discussions of these comparisons are shown below.

\section{Methodology roadmap}

The methodology roadmap of this review is illustrated in Figure 4.

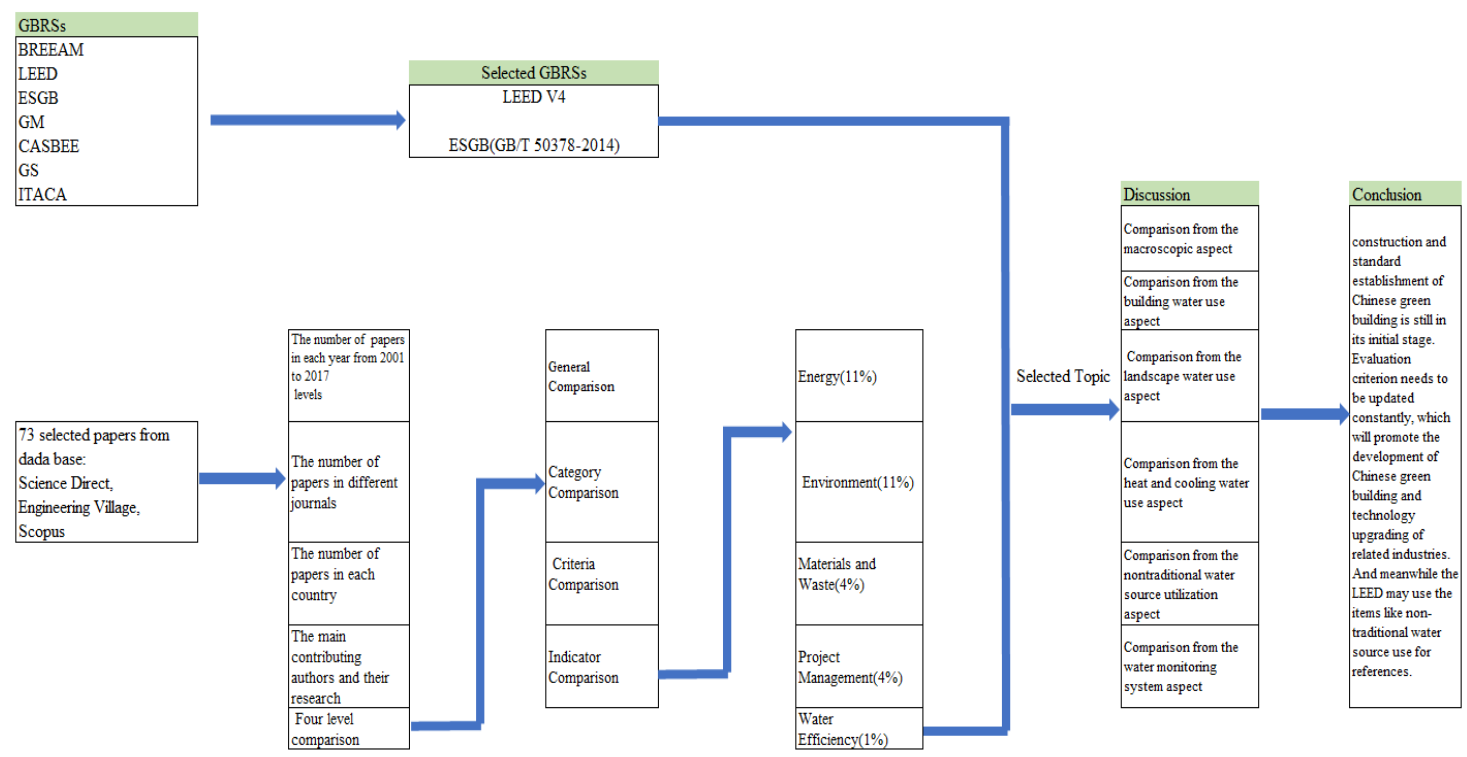

Figure 4. Methodology roadmap

\section{Discussion}

In this section, comparison analysis results focused on the water efficiency of the LEED and ESGB are carried out from six aspects, i.e. macroscopic, building water use, landscape water use, heat and cooling system water use, nontraditional water source utilization and water monitoring system. The differences between LEED and ESGB are related but not limited to (Awadh, 2017):

i. Considering various and interrelated categories

ii. Prioritizing and weighting concerns

\section{Macroscopic aspect}

From the macroscopic point of view, we can clearly find that:

(1) The water efficiency standards of ESGB and LEED are both composed of prerequisites items and credits items (Chen et al., 2015). The differences on prerequisites items are shown as follows:

(i) ESGB prerequisites items mainly focuses on the planning and designing of the whole water system, using water efficiency implements and setting up reasonable and thorough water system, but without any specific quantity indexes. LEED prerequisites items mainly focus on specific and measurable indexes, e.g. reducing the project's landscape water requirement by $30 \%$ from the maximum daily water requirement in this region, reducing building water consumption by $20 \%$ from the baseline and the basic 
requirements of water efficiency devices, which are detailed into the energy level as well as adoptive energy-saving and water-saving methods.

(ii) Water meter measurement and installation is regarded as a credit item in ESGB but a prerequisites item in LEED.

(2) The water saving standards of ESGB and LEED both focus on building water saving, landscape water saving and condensate water systems (Joustra and Yeh, 2009). They both suggest non-traditional water resource utilization and landscape plants without irrigation required. But their concerns are obviously different. ESGB concerns about daily water consumption, pipe leakage and safety in the whole contestant area; LEED water-saving percentage concerns about each tool, such as faucet, toilet, urinal, dishwasher and clothes washer, etc.

\section{Building water use aspect}

Inclusive contents, prerequisites items indexes, water-saving instruments baseline requirements are compared to analyze the similarities and differences of ESGB and LEED.

\section{(1) Inclusive contents}

From Table 5, we can see that ESGB covers more comprehensive contents. Besides water meter settings and sanitary devices of water-saving requirements, ESGB also concerns water saving and using quota, pipe network leakage, with or without overpressure outflow and the conditions of public bathroom, of which the water saving and using quota standard is Civil Building Water Saving Design Standard GB505552010. Valve devices with tight sealing, grading measuring water meter installation are adopted to reduce pipe network leakage. With less than $0.3 \mathrm{MPa}$ water supply pressures of water use spot, points of without overpressure outflow can be gotten. Showers with thermostatic control and temperature display function, user fees are promoted in public lavatory. Public water-saving consciousness is improved by connecting fees with water use. LEED does not have special requirements to public lavatory, but requires controlling the discharge water temperature and gives concrete measures, such as using back-fire arrangement, adding heat collecting system or recycling steam to boiler.

Table 5. Comparison table of LEED and ESGB on building water-saving contents

\begin{tabular}{c|c|c}
\hline Items & LEED & ESGB \\
\hline Water saving and consumption quota & $\times$ & $\sqrt{ }$ \\
Pipe network leakage & $\times$ & $\sqrt{ }$ \\
With or without overpressure outflow & $\times$ & $\sqrt{ }$ \\
Water monitoring system & $\sqrt{ }$ & $\sqrt{ }$ \\
Public bathroom & $\times$ & $\sqrt{ }$ \\
Water-saving requirements of sanitary instruments & $\sqrt{ }$ & $\sqrt{ }$ \\
\hline
\end{tabular}

\section{(2) Prerequisites items indexes}

ESGB prerequisites items indexes are mainly about macro-direction, which require setting out water resource utilization program, setting reasonable water supply and drainage system and selecting water-saving instruments. LEED requires specific and quantitative indexes, which includes: 
(i) Building water use: the total water-saving amount of toilets, urinals, towers, kitchen faucets etc reduces $20 \%$ by the baseline.

(ii) Clothes washers, dish washers, ice machine are all qualified of "Energy Star", and water amount of spray valve is no more than $0.082 \mathrm{~L} / \mathrm{s}$.

(iii) Regulating limiting value of maximum water amount to dish washers, food steamers and combination stove.

(iv) Water meter statistics can be checked for at least five years. LEED has more concrete prerequisites item indexes and is more difficult than ESGB to get points.

\section{(3) Water-saving instruments baseline requirements}

From the basic requirements of water-saving instruments in China and the US in Table 6, LEED water-saving instruments have better water-saving effect than ESGB in most cases. LEED has more strict water-saving efficiency requirements. For example, LEED requires $6 \mathrm{~L} /$ flush in toilets and ESGB single grade toilets require $6.5 \mathrm{~L} /$ flush. Urinal requirement is $3.8 \mathrm{~L} /$ flush in LEED and $4 \mathrm{~L} /$ flush in ESGB. The faucet flow seems to be the same, but LEED requires higher water flow than ESGB. Consequently, LEED has more strict requirements, which means China has quite a lot to do to improve on instruments using water-saving technology.

Table 6. Water-saving requirements baseline requirements

\begin{tabular}{|c|c|c|}
\hline Items & LEED & ESGB \\
\hline Toilet & $6 \mathrm{~L} /$ flush & $\begin{array}{l}\text { According to the limit value and GB25502-2010 level of } \\
\text { toilets water-use efficiency, the minimum requirements of } \\
\text { scoring are } 3 \text { grades: single grade } 6.5 \mathrm{~L} / \text { flush, double/big } \\
\text { grade } 6.5 \mathrm{~L} / \text { flush, small grade } 4.2 \mathrm{~L} / \mathrm{flush} \text { and the average } \\
\text { value is } 5.0 \mathrm{~L} / \mathrm{flush}\end{array}$ \\
\hline Urinal & $3.8 \mathrm{~L} /$ flush & $\begin{array}{l}\text { According to the limit value and GB28377-2012 level of } \\
\text { urinals water-use efficiency, the minimum requirements of } \\
\text { scoring are } 3 \text { grades, namely } 4 \text { L/flush }\end{array}$ \\
\hline \multirow{3}{*}{ Faucet } & $\begin{array}{c}\text { Under } 0.415 \mathrm{MPa}, \text { public } \\
\text { lavatory faucets }\end{array}$ & \multirow{3}{*}{$\begin{array}{l}\text { According to the limit value and GB25501-2010 level of } \\
\text { faucets water-use efficiency, the minimum requirements of } \\
\text { scoring are } 3 \text { grades, namely } 0.15 \mathrm{~L} / \mathrm{s}(0.1 \pm 0.01 \mathrm{MPa})\end{array}$} \\
\hline & $\begin{array}{c}0.03 \mathrm{~L} / \mathrm{s} \text {, private lavatory } \\
\text { faucets }\end{array}$ & \\
\hline & $\begin{array}{c}0.14 \mathrm{~L} / \mathrm{s}, \text { kitchen faucets } \\
0.14 \mathrm{~L} / \mathrm{s}\end{array}$ & \\
\hline Showerhead & $\begin{array}{c}\text { Under } 0.55 \mathrm{MPa} \text {, the flow } \\
\text { is } 0.16 \mathrm{~L} / \mathrm{s}\end{array}$ & Under $0.1 \pm 0.01 \mathrm{MPa}$, the flow is $0.15 \mathrm{~L} / \mathrm{s}$ \\
\hline
\end{tabular}

\section{Landscape water use aspect}

ESGB and LEED both suggest growing plants without permanent irrigation requirements. LEED requires reducing 30\% landscape water by maximum daily water consumption in the prerequisites item. More than $50 \%$ water saving percentage equals 1 point, and $100 \%$ water saving percentage equals 2 points. ESGB suggests adopting water-saving irritation system, setting up soil humidity sensor, and closing device on rainy days, etc. In a word, ESGB standard concerns whether there is corresponding measures, whereas LEED pays more attention on the ultimate water-saving effect and gives specific quantitative indexes.

ESGB encourages concerning rain utilization facilities. To be specific, during the stage of the landscape design, it is highly suggested that more than $60 \%$ of the 
landscape water amount should be derived from rain water. Besides, it requires using non-point source pollution controlling facilities to purify rain in landscape water and encourages using aquatic animals and plants to purify water.

\section{Heat and cooling system water use aspect}

LEED prerequisites items have regulations on cooling tower and evaporative condenser: water meter, conductance controller, overflow warning, valid drift canceller (controlling the maximum water drifting to $0.002 \%$ of recycling water in countercurrent tower and $0.005 \%$ of recycling water in disposable water quality) are needed. The requirements in credit item are:

(i) Disposable water quality analysis of cooling tower and evaporative condenser have to include $\mathrm{Ca}^{2+}$, total alkalinity, $\mathrm{SiO}_{2}, \mathrm{Cl}^{-}$and conductivity.

(ii) 1 point can be gained if the maximum cycle index of cooling tower reaches 10 . Whether improving supplementary water quality to 10 minimum cycle index, or using $20 \%$ non-drinking water source on the basis of 1 point can get 2 points.

ESGB suggests setting water-treatment facilities to water reuse system, such as enlarging water catching tray, setting balance tube or water tank, requiring more than $80 \%$ evaporation water consumption of water supplement in the cooling tower, or using non-evaporating cooling water consumption technology. ESGB approves utilizing nontraditional water source in cooling water supplementary system. The higher the percentage of non-traditional water source use is, the higher the points are.

In terms of similarity, both of LEED and ESGB put forward concrete and quantitative indexes to specific water-saving methods, process controlling and obtained results.

\section{Non-traditional water source utilization aspect}

LEED regulates that on the basis of control items $20 \%$ water-saving percentage, the additional water-saving percentage can be acquired by the alternative water source: the additional saving of $25 \%=1$ point, $30 \%=2$ points, $35 \%=3$ points, $40 \%=4$ points, $45 \%=5$ points, and $50 \%=6$ points (Alawneh et al., 2018).

ESGB points out that reclaimed water, rainwater and sea water etc. are included in non-traditional water source. Different points come from different building types. Quantitative criteria and non-traditional water source approving use direction are definite. ESGB approves and guides non-traditional water source to flush the indoor toilet, which can gain higher points. ESGB also approves using non-traditional water source as supplementary cooling water and landscape water and gives certain points according to the proportion.

As shown in Equation 2, the ratio of non-traditional water source use (NWSU)

$$
=\frac{\text { The total quantity of the NWSU }}{\text { The total quantity of the wateruse }} * 100 \%
$$

The NWSU includes the reuse water use, the rain water use, the sea water use and other types of NWSU. For the purpose to get the same score, the NWSU ratio requirement with the municipal reuse system (MRS) is higher than without MRS. For the new construction building, the NWSU is suggested to be used for outdoor greening, road watering and car washing. But if the project wants to get a higher score, the 
NWSU should take the indoor toilet flushing into consideration in order to increase the NWSU ratio. Because the latter need stricter water quality and deeper water treatment process.

From this point of view, the ESGB has a bit more detailed direction to guide the NWSU and help the owner to get more score. This item may be used by LEED for references.

\section{Water monitoring system aspect}

LEED and ESGB both approve setting water monitoring system to the kitchen, lavatory, greening, air conditioning system, swimming pool, and landscape, respectively, according to the purpose. LEED regards the water meter monitoring system as a control item and requires 5 years' water quantity record. $80 \%$ measurable water quantity of the total quantity is required in the credit item (Kern et al., 2016). While in ESGB, water monitoring system is only a credit item. But additional points can be gained by setting water measurement devices to measure water quantity according to fees and administrative units, respectively. The arrangements will help searching leakage and venting points of the pipe and reducing the leakage of water quantity.

\section{Conclusion}

In this review, a statistic analysis from the relevant papers of different GBRSs comparison has been carried out. It is clear that some existing GBRSs from the general, category and criteria levels have been compared in the past research efforts.. But little work has been done on the comparison of water efficiency. A thorough review of comparison on water efficiency between LEED and ESGB is carried out due to their similar structure and international repercussions. Six aspects including macroscopic, building water use, landscape water use, heat and cooling system use water, nontraditional water source utilization and water monitoring system are relatively compared in detail. In terms of their similarities, ESGB and LEED are both composed of control and scoring items. Moreover, both of the two standards concern building water-saving, landscape water-saving and condensate water systems, and approve nontraditional water source utilization and landscape plants without irrigation requirement. As for their differences, ESGB mainly concerns the planning and designing of the whole water system, using water-saving instruments, setting reasonable and thorough water system, without specific and detailed quantity indexes; whereas LEED mainly concerns specific and measurable indexes. Through contrastive analysis, a lot of work still needs to be done to improve the indexes control of instruments on water-saving efficiency for China. Relating to improve non-traditional water source use ratio, more effective and feasible measures, such as cooling water supplement, rainwater utilization in landscape water, indoor toilets flushing of non-traditional water source, are put forward. In conclusion, construction and standard establishment of Chinese green building is still in its initial stage. Evaluation criterion needs to be updated constantly, which will promote the development of Chinese green building and technology upgrading of related industries. And meanwhile the LEED may use the items like nontraditional water source use for references. 
Acknowledgements. This research was jointly supported by National Key Research and Development Program of China (2017YFF0209903, 2017YFF0209904), National Natural Science Foundation of China (51908334, 51908335), Shandong Provincial Natural Science Foundation (ZR2019BEE058, ZR2018BEE036), China Postdoctoral Science Foundation (2019M652427), and Doctoral Research Fund of Shandong Jianzhu University (XNBS1806, XNBS1822).

\section{REFERENCES}

[1] Alawneh, R., Mohamed Ghazali, F. E., Ali, H., et al. (2018): Assessing the contribution of water and energy efficiency in green buildings to achieve United Nations Sustainable Development Goals in Jordan. - Building and Environment 146: 119-132.

[2] Altomonte, S., Schiavon, S. (2013): Occupant satisfaction in LEED and non-LEED certified buildings. - Building and Environment 68: 66-76.

[3] Alyami, S. H., Rezgui, Y. (2012): Sustainable building assessment tool development approach. - Sustainable Cities and Society 5: 52-62.

[4] Awadh, O. (2017): Sustainability and green building rating systems: LEED, BREEAM, GSAS and Estidama critical analysis. - Journal of Building Engineering 11: 25-29.

[5] BREEAM (2016): What is BREEAM? - E-newsletter. https://www.breeam.com.

[6] CASBEE (2014): CASBEE information. http://www.ibec.or.jp/CASBEE/english/\#.

[7] Chen, H., Lee, W. L. (2013): Energy assessment of office buildings in China using LEED 2.2 and BEAM Plus 1.1. - Energy and Buildings 63: 129-137.

[8] Chen, X., Yang, H., Lu, L. (2015): A comprehensive review on passive design approaches in green building rating tools. - Renewable and Sustainable Energy Reviews 50: $1425-1436$.

[9] Cole, R. J. (2006): Shared markets: coexisting building environmental assessment methods. - Building Research \& Information 34: 357-371.

[10] Ding, G. K. (2008): Sustainable construction--the role of environmental assessment tools. - Journal of Environmental Management 86: 451-64.

[11] Ding, Z., Fan, Z., Tam, V. W. Y., et al. (2018): Green building evaluation system implementation. - Building and Environment 133: 32-40.

[12] Doan, D. T., Ghaffarianhoseini, A., Naismith, N., et al. (2017): A critical comparison of green building rating systems. - Building and Environment 123: 243-260.

[13] ESGB (2014): Evaluation Standard for Green Building. The Ministry of Housing and Urban-Rural Development announced the issuance of the national standard "Evaluation Standard for Green Building”. http://www.mohurd.gov.cn/wjfb/201508/t20150829_224219.html.

[14] Feng, H., Hewage, K. (2014): Energy saving performance of green vegetation on LEED certified buildings. - Energy and Buildings 75: 281-289.

[15] Gelowitz, M. D. C., Mcarthur, J. J. (2018): Insights on environmental product declaration use from Canada's first LEED v4 platinum commercial project. - Resources, Conservation and Recycling 136: 436-444.

[16] Green Mark (2013): About BCA Green Mark Scheme. https://www.bca.gov.sg/GreenMark/green_mark_buildings.html.

[17] Green Star (2015): Green Star Buildings. - https://new.gbca.org.au/green-star/.

[18] Gurgun, A. P., Komurlu, R., Arditi, D. (2015): Review of the LEED Category in Materials and Resources for Developing Countries. - Procedia Engineering 118: 11451152.

[19] Haapio, A., Viitaniemi, P. (2008): A critical review of building environmental assessment tools. - Environ. Impact Assess. Rev. 28: 469-482.

[20] He, Y., Kvan, T., Liu, M., et al. (2018): How green building rating systems affect designing green. - Building and Environment 133: 19-31. 
[21] Howard, G. S., Cole, D. A., Maxwell, S. E. (1987): Research productivity in psychology based on publication in the journals of the American Psychological Association. American Psychologist 42: 975-986.

[22] Hu, M., Peter, C., Sarah, G. (2017): Sustainable design rating system comparison using a life-cycle methodology. - Building and Environment 126: 410-421.

[23] ITACA (2015): ITACA Protocol. - http://www.itaca.org.

[24] Joustra, C., Yeh, D. H. (2009): Water conservation and wastewater reuse in a green building: an integrated approach towards LEED. - Proceedings of the Water Environment Federation 5: 2063-2086(24).

[25] Kang, H., Lee, Y., Kim, S. (2016): Sustainable building assessment tool for project decision makers and its development process. - Environmental Impact Assessment Review 58: 34-47.

[26] Kern, A. P., Antoniolli, C. B., Wander, P. R., et al. (2016): Energy and water consumption during the post-occupancy phase and the users' perception of a commercial building certified by Leadership in Energy and Environmental Design (LEED). - Journal of Cleaner Production 133: 826-834.

[27] Kyvelou, S., Sinou, M. (2013): Present and future of building performance assessment tools. - Management of Environmental Quality. An International Journal 17: 570-586.

[28] Lee, W. L (2012): Benchmarking energy use of building environmental assessment schemes. - Energy and Buildings 45: 326-334.

[29] Lee, W. L. (2013): A comprehensive review of metrics of building environmental assessment schemes. - Energy and Buildings 62(3): 403-413.

[30] LEED (2013): LEED is green building. - E-newsletter. https://new.usgbc.org/leed.

[31] Li, Y., Chen, X., Wang, X., et al. (2017): A review of studies on green building assessment methods by comparative analysis. - Energy and Buildings 146: 152-159.

[32] Lin, B., Liu, H. (2015): $\mathrm{CO}_{2}$ mitigation potential in China's building construction industry: a comparison of energy performance. - Building and Environment 94: 239-251.

[33] Liu, H., Lin, B. (2016): Energy substitution, efficiency, and the effects of carbon taxation: Evidence from China's building construction industry. - Journal of Cleaner Production 141: 1134-1144.

[34] Marjaba, G. E., Chidiac, S. E. (2016): Sustainability and resiliency metrics for buildings. Critical review. - Building and Environment 101: 116-125.

[35] Mattoni, B., Guattari, C., Evangelisti, L., et al. (2018): Critical review and methodological approach to evaluate the differences among international green building rating tools. - Renewable \& Sustainable Energy Reviews 82: 950-960.

[36] Nguyen, B. K., Altan, H. (2011): Comparative review of five sustainable rating systems. - Pore. Eng. 21: 376-386.

[37] Say, C., Wood, A. (2012): Sustainability rating systems around the world. - Council on Tall Buildings and Urban Habitat - Review 18-29: 759-888.

[38] Schwartz, Y., Raslan, R. (2013): Variations in results of building energy simulation tools, and their impact on BREEAM and LEED ratings: a case study. - Energy and Buildings 62: 350-359.

[39] Sharifi, A. (2016): A critical review of selected tools for assessing community resilience. - Ecological Indicators 69: 629-647.

[40] Sharifi, A., Murayama, A. (2013): A critical review of seven selected neighborhood sustainability assessment tools. - Environmental Impact Assessment Review 38: 73-87.

[41] Sharifi, A., Murayama, A. (2014): Neighborhood sustainability assessment in action: Cross-evaluation of three assessment systems and their cases from the US, the UK, and Japan. - Building and Environment 72: 243-258.

[42] Sharifi, A., Yamagata, Y. (2016): Principles and criteria for assessing urban energy resilience: a literature review. - Renewable and Sustainable Energy Reviews 60: 16541677. 
[43] Smith, P. (2005): Architecture in a Climate of Change: A Guidance to Sustainable Design. - Architectural Press, Oxford.

[44] U. S. Green Building Council (2018): USGBC. - usgbc.org.

[45] UNEP SBCI (2008): Buildings and Climate Change. - United Nations Environment Programme, Nairobi.

[46] Wang, B. Y., et al. (2016): Measured energy use and indoor environment quality in green office buildings in China. - Energy and Buildings 129: 9-18.

[47] Wang, S., Yan, C., Xiao, F. (2012): Quantitative energy performance assessment methods for existing buildings. - Energy and Buildings 55: 873-888.

[48] WBCSD (2008): Energy Efficiency in Buildings, Business Realities and Opportunities. The World Business Council for Sustainable Development, Geneva.

[49] Wu, P., Mao, C., Wang, J., et al. (2016): A decade review of the credits obtained by LEED v2.2 certified green building projects. - Building \& Environment 102: 167-178.

[50] Wu, P., Song, Y., Shou, W., et al. (2017): A comprehensive analysis of the credits obtained by LEED 2009 certified green buildings. - Renewable \& Sustainable Energy Reviews 68: 370-379.

[51] Yudelson, J. (2008): The green building revolution. - Heating/Piping/Air Condition. Eng. 80: 8.

[52] Zhu, H., Hong, J., Shen, G. Q., et al. (2017): The exploration of the life-cycle energy saving potential for using prefabrication in residential buildings in China. - Energy and Buildings 166: 561-570. 